\title{
Migration of esophageal self-expandable metal stent to the pleural cavity
}

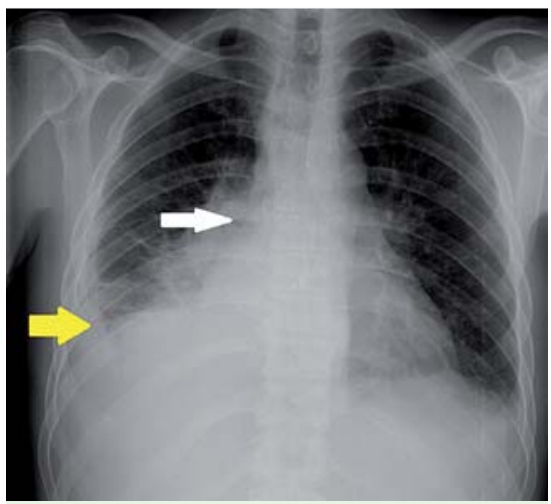

Fig. 1 Chest radiograph showing metal esophageal stent (white arrow), mediastinal enlargement with right pulmonary infiltrates, and pleural effusion (yellow arrow).

A 41-year-old man presented with dysphagia secondary to squamous cell carcinoma of the esophagus, staged as T4N1M0. A covered self-expandable metal stent (SEMS) (Choostent; Solco Intermed, Seoul, Korea) was inserted for symptomatic relief, chemoradiotherapy was performed with carboplatin and 5fluorouracil, and this was followed by radiotherapy to deliver $39.6 \mathrm{~Gy}$ in 22 daily fractions.

The patient presented with cough, thoracic pain, and vomiting 3 months after SEMS placement. The chest radiograph revealed mediastinal enlargement, right pleural effusion, and infiltrates ( $\bullet$ Fig. 1). Upper endoscopy revealed patency of the stent with the distal end of the stent ending in a closed cavity ( $\bullet$ Fig. 2 a), which after aspiration had an appearance compatible with that of the pleural cavity ( Fig. 2b; $\bullet$ Video 1). Computed tomography (CT) confirmed migration of the esophageal SEMS to the pleural space,

\section{Video 1}

Upper endoscopy video showing patency of the stent and progression through the stent, arriving at a closed cavity with an appearance suggestive of the pleural space.
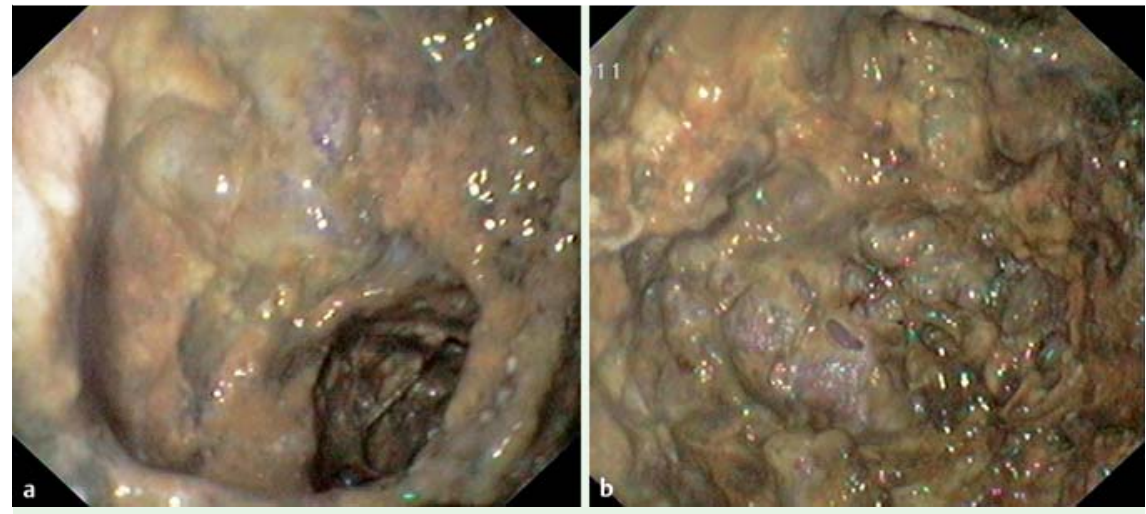

Fig. 2 Upper endoscopy view at the end of the stent, showing: a a closed cavity; $\mathbf{b}$ after aspiration, the cavity had an appearance compatible with that of the pleural cavity.

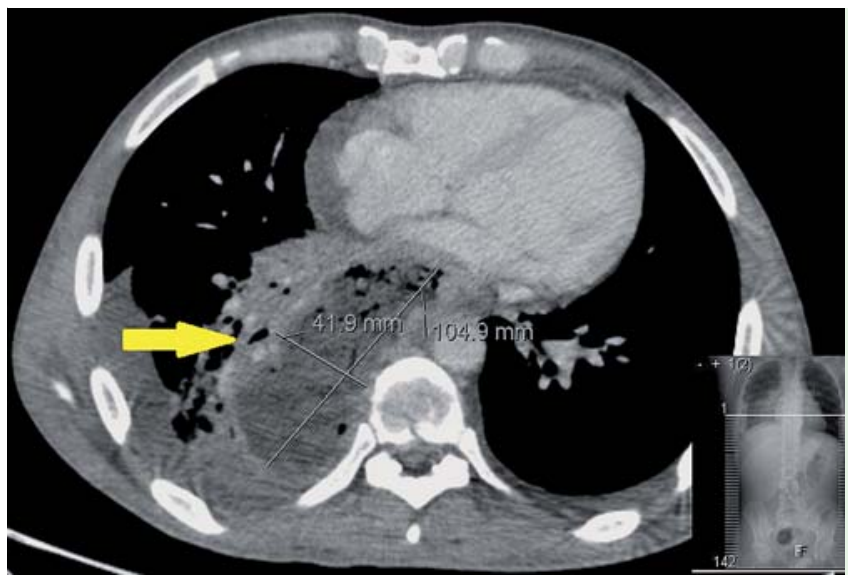

Fig. 3 Computed tomography (CT) image revealing a $105 \times 42$-mm cavity in the pleural space (arrow).

secondary to tumor growth, with formation of a $105 \times 42-\mathrm{mm}$ cavity ( $\bullet$ Fig. 3 ). Multiple hepatic metastases were detected.

After medicosurgical discussion, a derivative lateral esophagostomy and jejunostomy were performed, and broad spectrum antibiotics given. CT performed after 15 days revealed resolution of the cavity. SEMS placement provides effective palliation for patients with esophageal cancer [1]. However, its safety in patients undergoing chemoradiotherapy is uncertain $[1,2]$. In fact, SEMS migration is common following down-staging of esophageal carcinoma with chemoradiotherapy, with several published case reports of prosthesis migration in this context [3-5]. How- ever, to the best of our knowledge, this is the first report of migration of an esophageal SEMS to the pleural cavity. This case is also original for the fact that migration of the prosthesis was not related to down-staging of the tumor after chemoradiotherapy. We hypothesize that fragility of the esophageal wall due to radiation injury might have favored prosthesis migration in the setting of tumor growth. This hypothesis is supported by the previously described association between SEMS placement with chemoradiotherapy and esophageal perforation [2].

\section{Endoscopy_UCTN_Code_TTT_1AO_2AZ}

Competing interests: None 
F. Ferreira ${ }^{1,2}$, R. Gonçalves ${ }^{1}$, F. VilasBoas $^{1}$, G. Macedo ${ }^{1,2}$

1 Gastroentrology Department, Hospital de São João, Porto, Portugal

2 Faculty of Medicine, Porto, Portugal

\section{References}

1 Sreedharan A, Harris K, Crellin A et al. Interventions for dysphagia in oesphageal cancer. Cochrane Database Syst Rev 2009; 4: 1 - 102

2 Sumiypshi T, Gotoda T, Rembacken $B$ et al. Morbidity and mortality after self-expandable metallic stent placement in patients with progressive or recurrent esophageal cancer after chemoradiotherapy. Gastrointest Endosc 2003; 57: $882-885$

3 Furlong H, Nasr A, Walsh TN. Gastropleural fistula: a complication of esophageal sel-expanding metallic stent migration. Endoscopy 2009; 41: E38 - 39

4 Reddy VM, Sutton CD, Miller AS. Terminal ileum perforation as a consequence of a migrated and fractured oesophageal stent. Case Rep Gastroenterol 2009; 3: 61 - 66

5 Thuraisingam Al, Hughes ML, Smart HL. Down-staging of an advanced esophageal carcinoma with chemoradiotherapy leading to stent migration necessitating colectomy. Gastrointest Endosc 2004; 59: 457-460
Bibliography

DOI $10.1055 / \mathrm{s}-0030-1256424$

Endoscopy 2011; 43: E286 -E287

(c) Georg Thieme Verlag KG Stuttgart · New York . ISSN 0013-726X

\section{Corresponding author}

\section{F. Ferreira, MD}

Hospital de São João

Serviço de Gastrenterologia

Alameda Professor Hernâni Monteiro

4200-319 Porto

Portugal

Fax: +351-225-507742

fredericoferreira2@hotmail.com 